San Jose State University

SJSU ScholarWorks

Master's Projects

Master's Theses and Graduate Research

Fall 2013

\title{
Pattern Discovery of Sequential Symbolic Data using Automata with an application to Author Identification
}

Nikhil Kalantri

San Jose State University

Follow this and additional works at: https://scholarworks.sjsu.edu/etd_projects

Part of the Computer Sciences Commons

\section{Recommended Citation}

Kalantri, Nikhil, "Pattern Discovery of Sequential Symbolic Data using Automata with an application to Author Identification" (2013). Master's Projects. 333.

DOI: https://doi.org/10.31979/etd.uhdr-ae3z

https://scholarworks.sjsu.edu/etd_projects/333

This Master's Project is brought to you for free and open access by the Master's Theses and Graduate Research at SJSU ScholarWorks. It has been accepted for inclusion in Master's Projects by an authorized administrator of SJSU ScholarWorks. For more information, please contact scholarworks@sjsu.edu. 


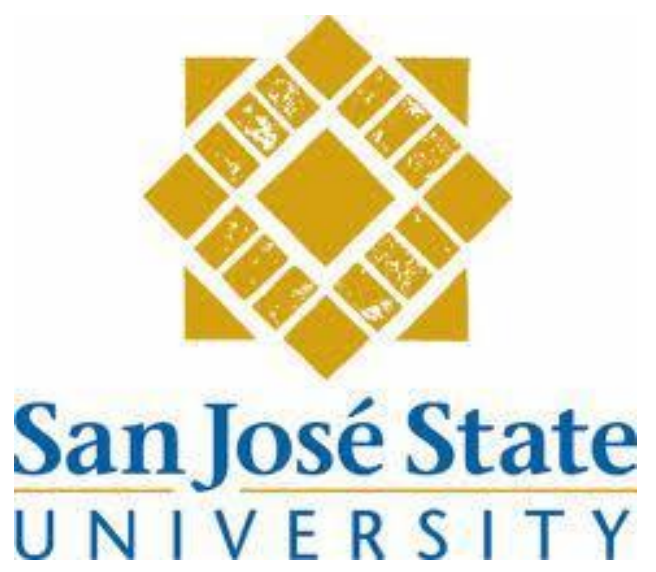

\title{
Pattern Discovery of Sequential Symbolic Data using Automata with an application to Author Identification
}

\author{
A Thesis \\ Presented to \\ The Faculty of the Department of Computer Science \\ San José State University \\ In Partial Fulfillment \\ of the Requirements for the Degree \\ Master of Science \\ by \\ Nikhil Kalantri \\ December 2013
}


(C) 2013

Nikhil Kalantri

ALL RIGHTS RESERVED 


\title{
SAN JOSE STATE UNIVERSITY
}

The Designated Thesis Committee Approves the Thesis Titled

\section{Pattern Discovery of Sequential Symbolic Data using Automata with an application to Author Identification}

\author{
by \\ Nikhil Kalantri \\ APPROVED FOR THE DEPARTMENT OF COMPUTER SCIENCE \\ SAN JOSÉ STATE UNIVERSITY
}

December 2013

Dr. T. Y. Lin, Department of Computer Science

Date

Dr. Chris Tseng, Department of Computer Science

Date

Mr. Amit Sant, Software Engineer at Apple

Date 


\begin{abstract}
Author Identification is the process of identifying a piece of text to ascertain if it has an inherent writing style or pattern based on a certain author. Almost all literary books can be accredited to a certain author since it has been signed. However, there also exist a plethora of unfinished books or manuscripts that could be attributed to a range of possible authors. For example, William Shakespeare has written many plays that have not been signed by him. In order to assess the importance of such texts that do not bear the authors signature, it could be vital to know who was the writer. I plan to solve this dilemma using the characteristics of finite state automata coupled with the ALERGIA algorithm.
\end{abstract}




\section{ACKNOWLEDGEMENTS}

I would like to acknowledge and extend my heartfelt gratitude to the following people who have made the completion of this project successful. I thank my project advisor Dr. T.Y. Lin, for the vital encouragement and support. You have been a tremendous mentor throughout. Working on this project was a challenging experience. Your advice and guidance will always be with me and help me grow as an individual.

I would also like to thank my committee members Dr. Tseng and Mr. Amit Sant for their support and patience. I also want to thank you for the being part of this exciting journey.

I want to thank our department for providing us with the necessary software required in our project. I'm also thankful to the library for providing necessary books and materials required to learn different concepts for our project.

A special thanks to my family. Words cannot express how grateful I am to my mother, father and sister for all the sacrifices you have made for me. Your prayers and blessings have helped me sustain this far. At the end, I would like to express appreciation to my incredible friends Onkar, Akanksha and Mrinmai who always stood by me whenever I needed them. 


\section{TABLE OF CONTENTS}

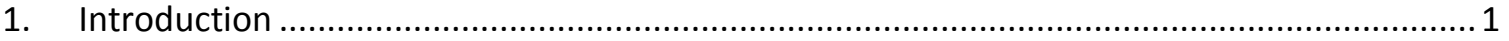

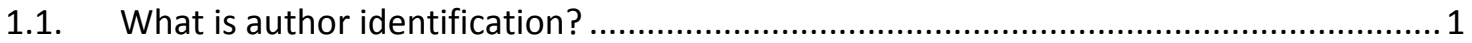

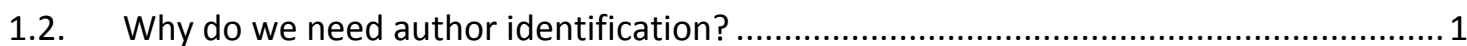

1.3. Why use computational/statistical methods? ........................................................ 1

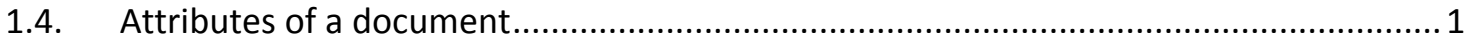

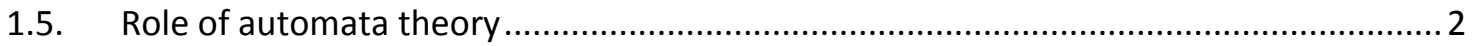

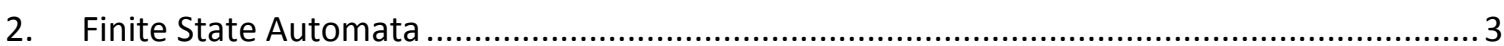

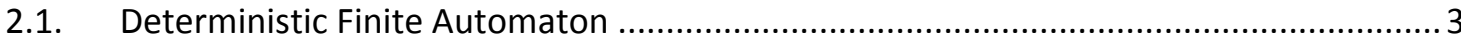

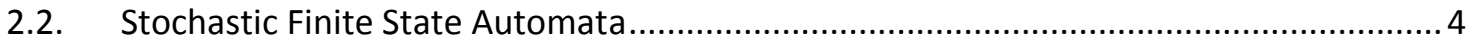

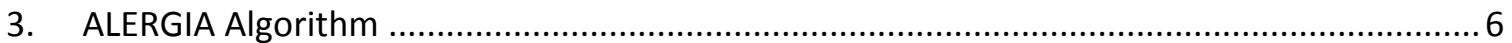

4. Analyzing text using automata based modeling .................................................................. 9

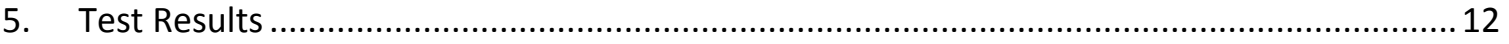

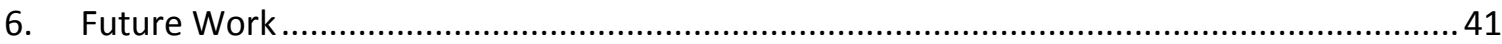

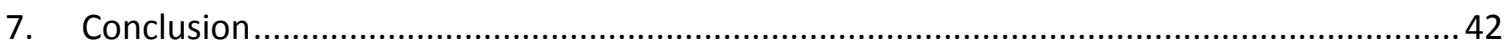

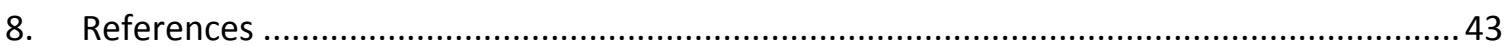

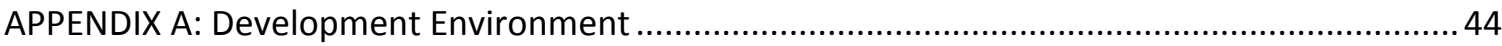

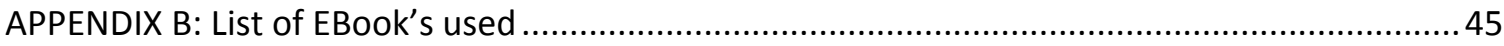




\section{LIST OF TABLES}

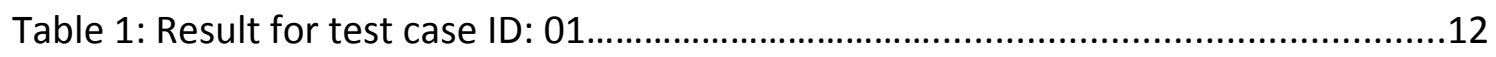

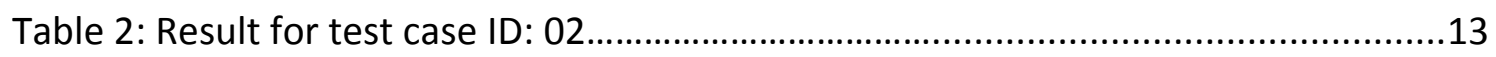

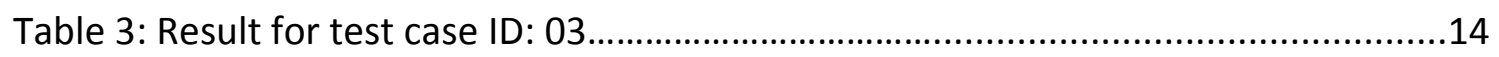

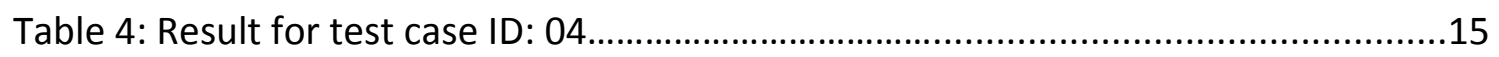

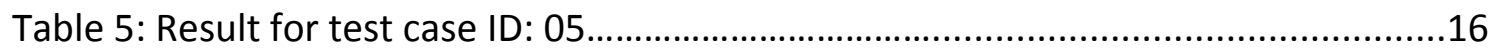

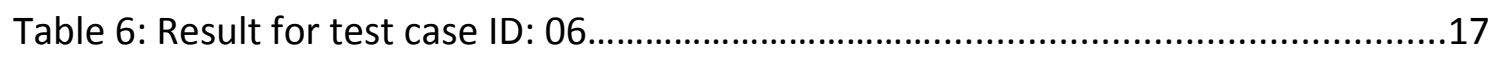

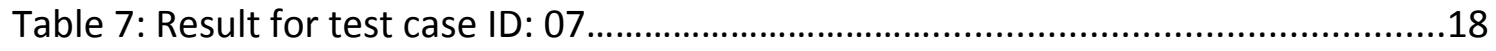

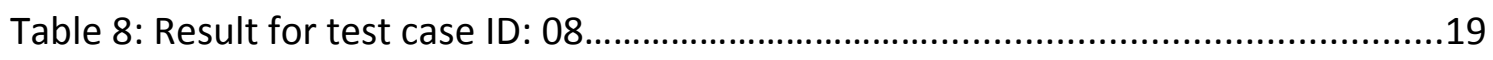

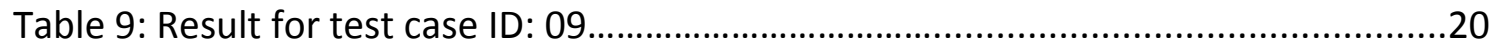

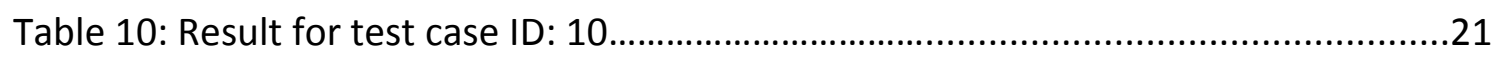

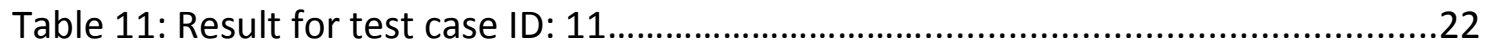

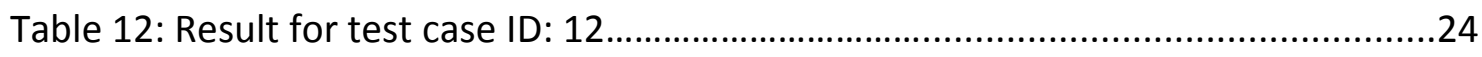

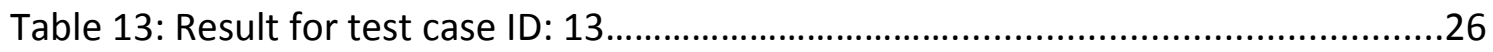

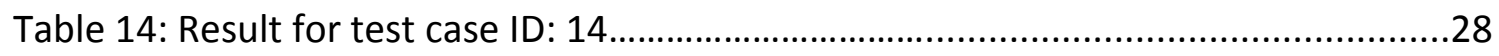

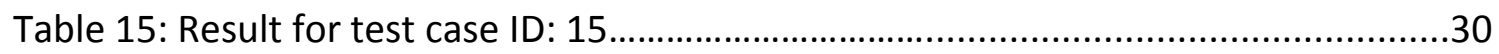

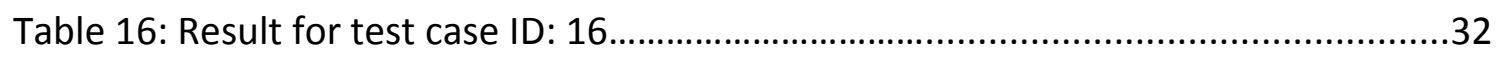

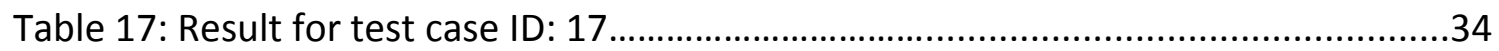

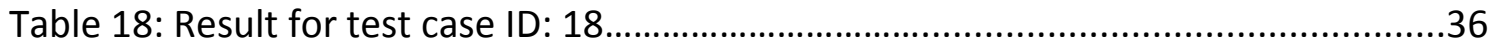

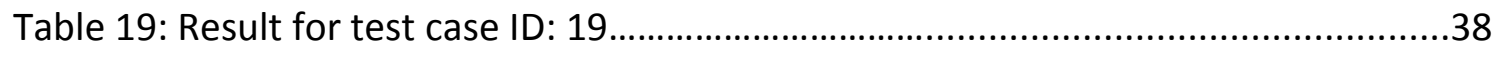

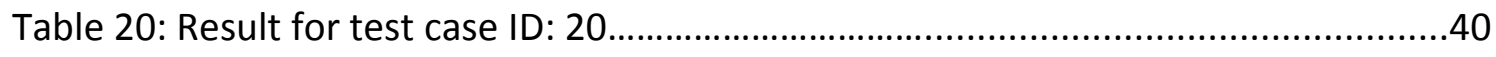

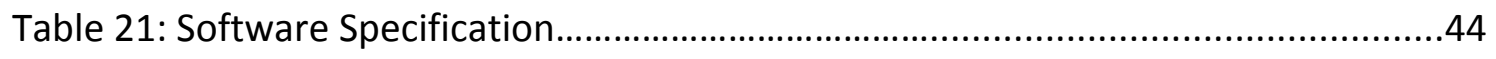

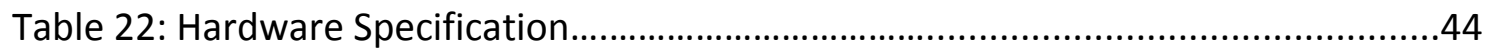

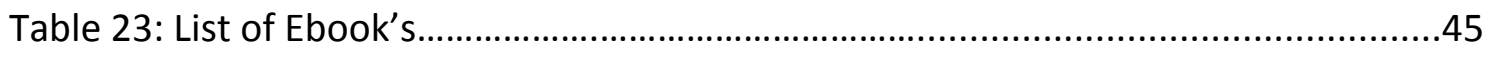




\section{LIST OF FIGURES}

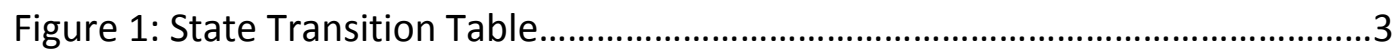

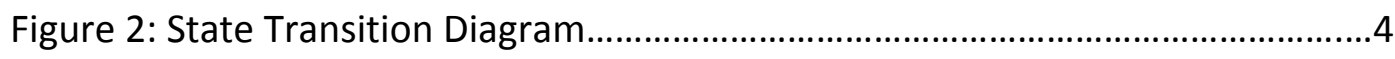

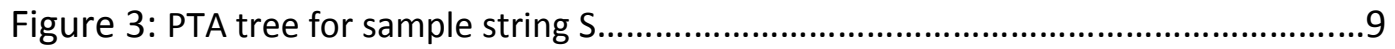

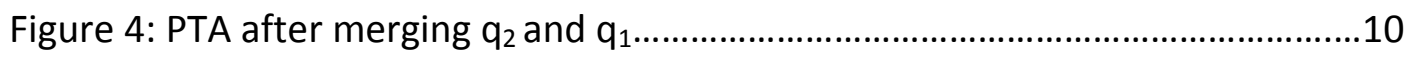

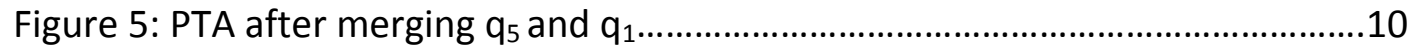

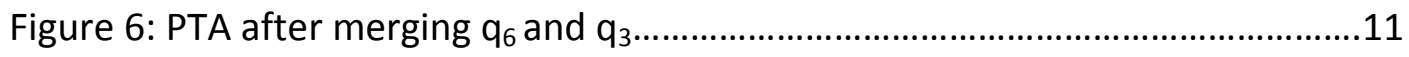




\section{Introduction}

\subsection{What is author identification?}

It is the process of identifying the creator of a written text through computational, statistical analysis. This analysis assists in capturing an author's inherent writing style and this pattern can be used to find the source of an unsigned document.

\subsection{Why do we need author identification?}

Author identification is an important problem in many areas ranging from information retrieval and computational linguistics to journalism and law where this could potentially help in saving lives like discover the author of a ransom note.

\subsection{Why use computational/statistical methods?}

Every author has a unique style of writing just like a human fingerprint. The human eye cannot recognize or pick up all the varying aspects of a document. Computational methods allow and aid humans to improve pattern analysis by exploring and uncovering these hidden traits of documents. A famous example to identify authors was shown by Professor Arthur Kinney in 2006. He proves that all unsigned Shakespeare documents or plays that were attributed to him, were indeed his with the help of statistical analysis.

\subsection{Attributes of a document}

Attributes are divided into four broad categories - Lexical, syntactic, structural and content-specific. These attributes help differentiate between authors. A few examples for each of the attributes are given below.

- Lexical: average number of words in a sentence, length of the word, total words.

- Syntactic: punctuations.

- Structural: font types, headers, footers, paragraph style.

- Content-specific: Number of stop words or abbreviations, gender or age based words. 


\subsection{Role of automata theory}

The objective of this paper is to analyze sample texts based on automata [5][12] theory.

This is achieved by generating a prefix tree acceptor by filtering out the stop words in a book and then applying the Alergia algorithm to check the compatibility of corresponding states. The algorithm regenerates the PTA iteratively through merging all compatible or equivalent states. 


\section{Finite State Automata}

\subsection{Deterministic Finite Automaton}

Definition: A deterministic finite automaton consists of the following parameters:

- A finite set of states denoted by $Q$

- A finite set of symbols $\Sigma$

- A transition function that takes a state and a symbol as arguments and returns a state. It is denoted by $\delta$.

- The start state denoted by $q_{0}$

- Set of final or accepting states denoted by $F$

Therefore, we have $q_{0} \in Q$ and $F \subseteq Q$.

So a DFA is mathematically represented as a 5 -uple $\left(Q, \Sigma, \delta, q_{0}, F\right)$.

The transition function $\delta$ is a function in

$\mathrm{Q} \times \Sigma \rightarrow \mathrm{Q}$

$\mathrm{Q} \times \Sigma$ is the set of 2 -tuples $(\mathrm{q}, \mathrm{a})$ with $\mathrm{q} \in \mathrm{Q}$ and $\mathrm{a} \in \Sigma$

A DFA with a transition table is given as

\begin{tabular}{c||c|c} 
& 0 & 1 \\
\hline$\rightarrow q_{0}$ & $q_{2}$ & $q_{0}$ \\
$* q_{1}$ & $q_{1}$ & $q_{1}$ \\
$q_{2}$ & $q_{2}$ & $q_{1}$
\end{tabular}

Figure 1: State transition table 
This transition table defines the following transition diagram,

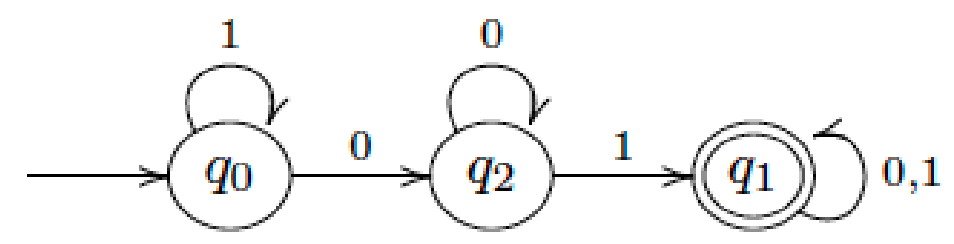

Figure 2: State Transition Diagram

Therefore,

$Q=\left\{q_{0}, q_{1}, q_{2}\right\}$

Start state $q_{0}$

$F=\left\{q_{1}\right\}$

$\Sigma=\{0,1\}$

$\delta$ is a function from $Q \times \Sigma$ to $Q$

$\delta: Q \times \Sigma \rightarrow Q$

$\delta\left(q_{0}, 1\right)=q_{0}$

$\delta\left(q_{0}, 0\right)=q_{2}$

\subsection{Stochastic Finite State Automata}

A stochastic finite state automaton [9] provides transition probabilities to each of the next states in addition to providing the finite state automata [5][12] for the given input.

For example, consider input symbols $b_{1}, b_{2}$. Now, there is a possibility of two arbitrary transitions $\delta\left(q, b_{1}\right)$ or $\delta\left(q, b_{2}\right)$. SFA helps us in analyzing and evaluating the probability of a transition to each of the states.

The probability function to calculate arbitrary transitions is given by,

$p_{i f}+\sum_{q_{j} \in Q} \sum_{a \in A} p_{i j}(a)=1$ 
This shows that the sum of probabilities that start and end at node $q_{i}$ is always equal to 1.

The language generated by stochastic finite automata [9] is known as stochastic regular language (SRL). 


\section{ALERGIA Algorithm}

The Alergia algorithm specializes in merging the states of a generated automaton from a probabilistic point of view. Alergia is a learning algorithm. Consider a sample set containing duplicate strings; the algorithm can learn its Deterministic Frequency Finite Automata [5] and also the Deterministic Probabilistic Finite Automata [5].

When the probability of appearance of a string follows a well-defined distribution, Alergia has the ability to take advantage of this and merge states when the resulting automaton is compatible with the observed frequency of strings.

First the algorithm generates a prefix tree from the input strings and analyzes the relative frequency of outgoing arcs at every node. The prefix tree captures this information.

Let $n_{i}$ be the number of strings arriving at node $q_{i}$.

$f_{i}(a)$ : Number of strings following $\operatorname{arc} \delta_{i}(a)$

$f_{i}(\#)$ : Number of strings terminating at node $q_{i}$

Calculate the following probabilities:

$p_{i}(a)=f_{i}(a) / n_{i}$

$p_{\text {if }}=f_{i}(\#) / n_{i}$

The algorithm compares corresponding nodes $\left(q_{i}, q_{j}\right)$. The value of $j$ varies from 2 to $t$ and $i$ varies from 1 to $j-1$.

When the probabilities of two corresponding states are equal, they are considered equivalent and this rule applies to their corresponding children. 
If the difference between the probabilities of the two states is less than the acceptance range $\alpha$, these states are considered as compatible. Recursively, the child nodes are also considered compatible.

A false value will be returned if the probability difference is greater than the acceptance rate. The formula to compare two states is given by the Hoeffding bound:

$\left|\frac{f}{n}-\frac{f^{\prime}}{n^{\prime}}\right|<\sqrt{\frac{1}{2} \log \frac{2}{\alpha}}\left(\frac{1}{\sqrt{n}}+\frac{1}{\sqrt{n^{\prime}}}\right)$

There are 3 algorithms that we consider:

Algorithm COMPATIBLE

Input:

$\mathrm{i}, \mathrm{j}:$ nodes

Output:

Boolean

Begin

If different $\left(n_{i}, f_{i}(\#), n_{j}, f_{j}(\#)\right)$

Return false

Endif

Do $(\forall \mathrm{a} \in A)$

If different $\left(n_{i}, f_{i}(a), n_{j}, f_{j}(a)\right)$

Return false

End if

If not compatible $(\delta(i, a), \delta(j, a))$

Return false

End if

End do

Return true

End algorithm 


\section{Algorithm DIFFERENT}

Input:

$n, n^{\prime}$ : number of strings arriving at each node.

$f, f^{\prime}$ : number of strings ending or following a given arc

Output:

Boolean

Begin

$$
\text { Return }\left|\frac{f}{n}-\frac{f^{\prime}}{n^{\prime}}\right|<\sqrt{\frac{1}{2} \log \frac{2}{\alpha}}\left(\frac{1}{\sqrt{n}}+\frac{1}{\sqrt{n^{\prime}}}\right)
$$

End Algorithm

\section{Algorithm ALERGIA}

Input:

$S:$ sample set of strings

$\alpha: 1$-confidence level

Output:

Stochastic DFA

Begin

$A$ = stochastic Prefix Tree Acceptor from $S$

Do (for $\mathrm{j}$ = successor (first node $(A)$ ) to last node $(A)$ )

Do (for I = first node $(A)$ to $j$ )

If compatible $(I, j)$

Merge $(A, \mathrm{i}, \mathrm{j})$

Determinize $(A)$

Exit (i-loop)

End if

End for

End for

Return $A$

End algorithm 


\section{Analyzing text using automata based modeling}

Consider an input string,

$S=\{110,-,-, 0,-,-, 00,-, 00,-,-, 100,-,-, 10110\}$

Let $\alpha=0.8$

Step 1: Build the Prefix Tree Acceptor tree

Therefore, $\curlyvee=\sqrt{\frac{1}{2} \log \frac{2}{\alpha}} \approx 0.67$

Every arc for each transition has a label with 0 or 1 and the number of strings in the input using that arc is shown in brackets. Then the algorithm checks for the equivalence of corresponding nodes. This is achieved by comparing their SFA probabilities.

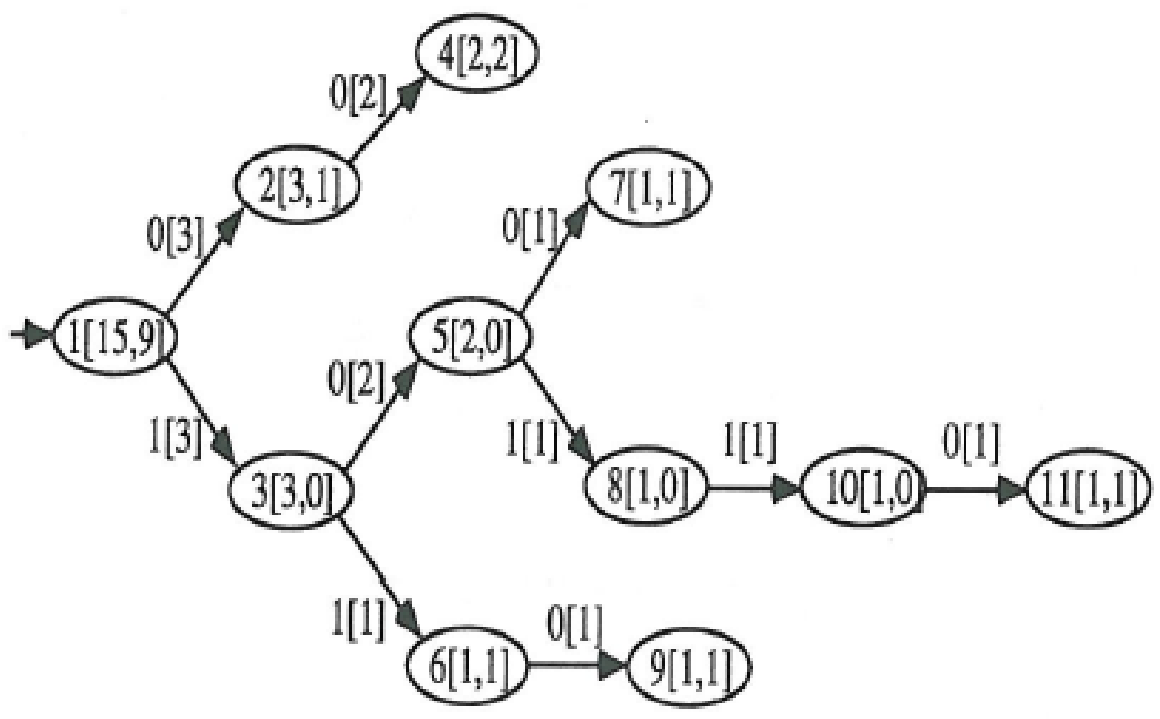

Figure 3: PTA tree for sample string $S$ [9]

Step 2: Minimize the states using the Hoeffding bound.

We generate the Deterministic Frequency Finite Automaton by applying the algorithm to merge compatible nodes. After merging thrice with $\alpha=0.8$, we get 


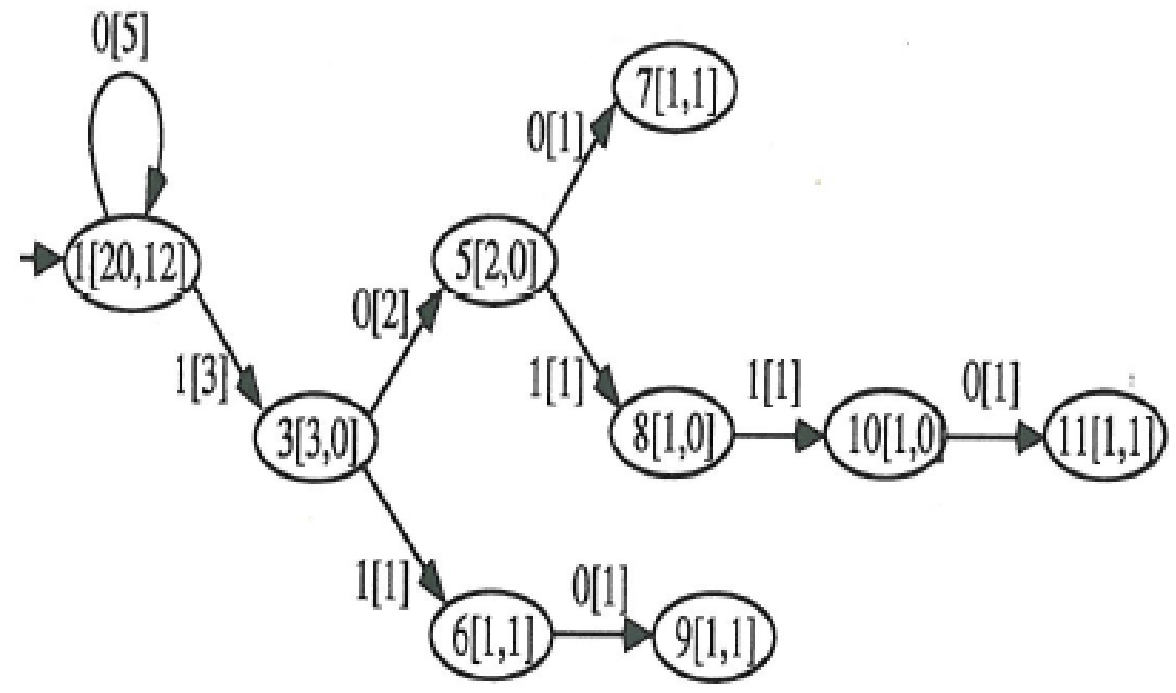

Figure 4: PTA after merging $q_{2}$ and $q_{1}[9]$

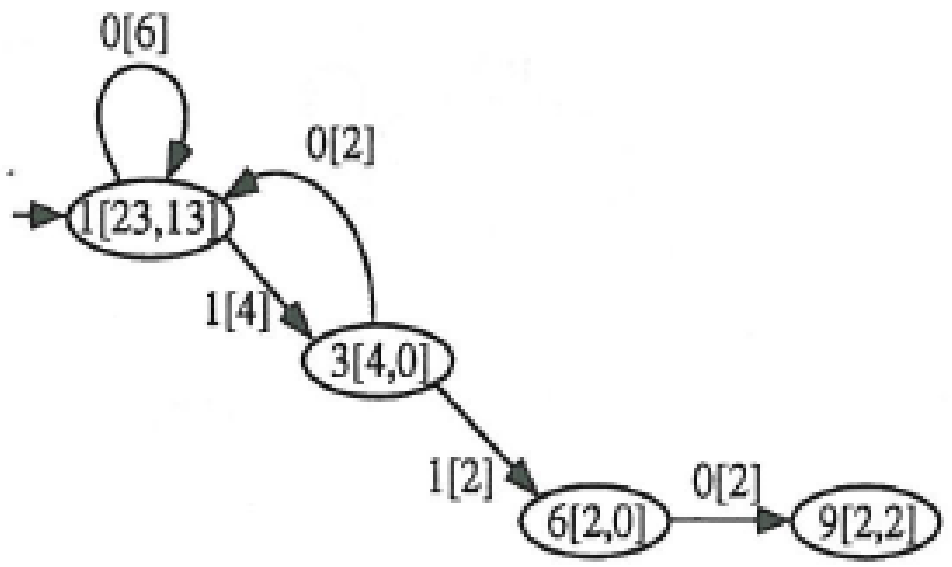

Figure 5: PTA after merging $q_{5}$ and $q_{1}$ [9] 


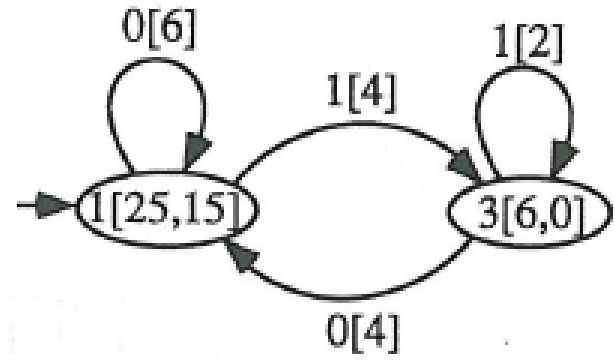

Figure 6: PTA after merging $q_{6}$ and $q_{3}$ [9] 


\section{Test Results}

Test case ID: 01

Start $\alpha: 0.1$

Increment per iteration: 0.1

Maximum $\alpha: 1.01$

Learn from book: JK Rowling - HPO.txt

Test books:

- JK Rowling - HPO.txt

- JK Rowling - HP1.txt

- James Matthew Barrie - Peter Pan.txt

Test Output:

\begin{tabular}{|c|c|c|c|c|}
\hline i & Alpha & $\operatorname{Doc} 01\left(\frac{\circ}{6}\right)$ & $\operatorname{Doc} 02\left(\frac{\circ}{6}\right)$ & Doc $03(\%$ \\
\hline-- & ---- & ------- & ------- & ----- \\
\hline 1 & 0.10 & 99.981 & 96.949 & 89.933 \\
\hline 2 & 0.20 & 99.979 & 97.816 & 87.154 \\
\hline 3 & 0.30 & 99.978 & 91.365 & 81.706 \\
\hline 4 & 0.40 & 99.975 & 88.721 & 74.585 \\
\hline 5 & 0.50 & 99.972 & 82.808 & 71.283 \\
\hline 6 & 0.60 & 99.971 & 79.368 & 67.767 \\
\hline 7 & 0.70 & 99.965 & 77.896 & 53.931 \\
\hline 8 & 0.80 & 99.962 & 71.540 & 35.822 \\
\hline 9 & 0.90 & 99.955 & 69.571 & 33.446 \\
\hline 10 & 1.00 & 99.951 & 68.831 & 29.595 \\
\hline
\end{tabular}

Table 1: Result for test case ID: 01

Expected Result: There should be a high percentage match for the books written by the same author when $\alpha=1.00$.

Actual Result: The output indicates that the books written by J.K Rowling have a higher match as compared with other authors.

Pass/Fail: The test has passed. 
Test case ID: 02

Start $\alpha: 0.1$

Increment per iteration: 0.1

Maximum $\alpha: 1.01$

Learn from book: JK Rowling - HPO.txt

Test books:

- JK Rowling - HP0.txt

- JK Rowling - HP1.txt

- Dante Alighieri - The Divine Comedy.txt

Test Output:

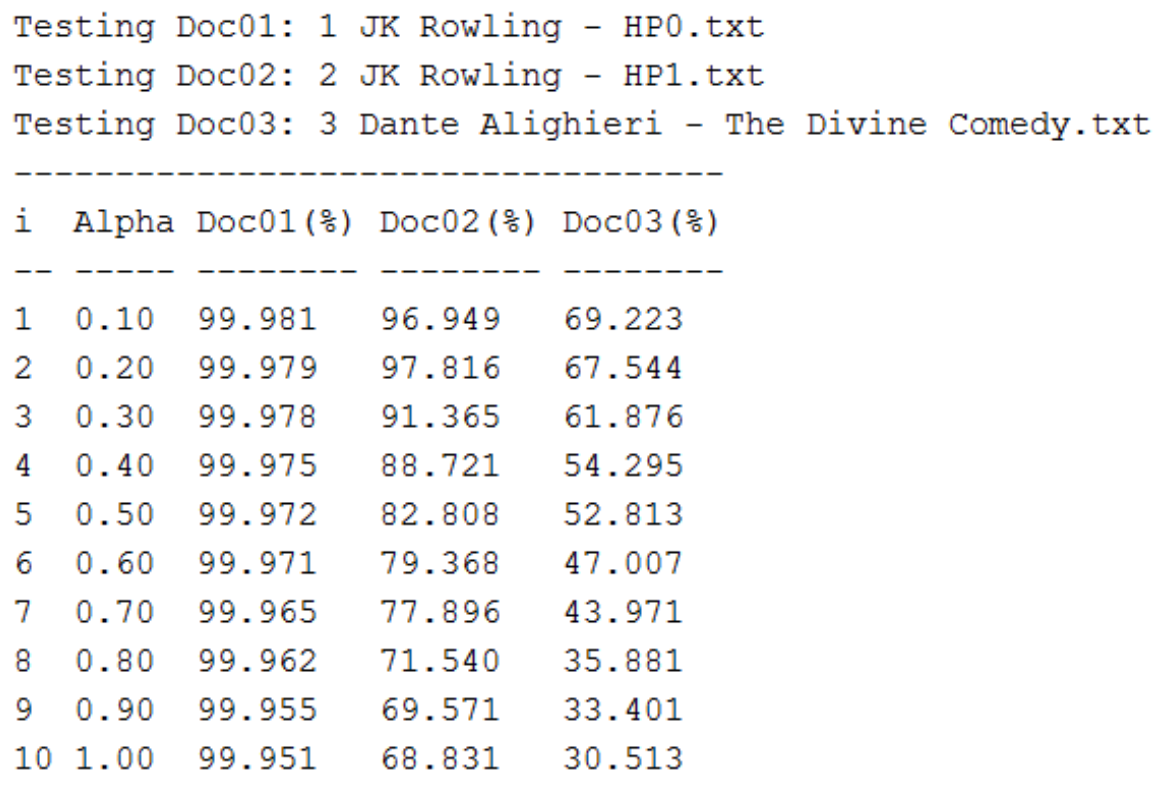

Table 2: Result for test case ID: 02

Expected Result: There should be a high percentage match for the books written by the same author when $\alpha=1.00$.

Actual Result: The output indicates that the books written by J.K Rowling have a higher match as compared with other authors.

Pass/Fail: The test has passed. 
Test case ID: 03

Start $\alpha: 0.1$

Increment per iteration: 0.1

Maximum $\alpha: 1.01$

Learn from book: JK Rowling - HPO.txt

Test books:

- JK Rowling - HP0.txt

- JK Rowling - HP1.txt

- Arthur Conan Doyle -The Adventures of Sherlock Holmes.txt

Test Output:

Testing Doc01: 1 JK Rowling - HP0.txt

Testing Doc02: 2 JK Rowling - HP1.txt

Testing Doc03: 3 Arthur Conan Doyle -The Adventures of Sherlock Holmes.txt

i Alpha Doc01 (\%) Doc02 (\%) Doc03 (\%)

-- ----- -------- -------- --------

$\begin{array}{lllll}1 & 0.10 & 99.981 & 96.949 & 59.282\end{array}$

$2 \quad 0.20 \quad 99.979 \quad 97.816 \quad 55.509$

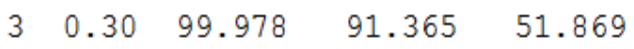

$\begin{array}{lllll}4 & 0.40 & 99.975 & 88.721 & 44.239\end{array}$

$\begin{array}{lllll}5 & 0.50 & 99.972 & 82.808 & 42.887\end{array}$

$\begin{array}{lllll}6 & 0.60 & 99.971 & 79.368 & 37.012\end{array}$

$\begin{array}{lllll}7 & 0.70 & 99.965 & 77.896 & 33.996\end{array}$

$\begin{array}{lllll}8 & 0.80 & 99.962 & 71.540 & 25.827\end{array}$

$\begin{array}{lllll}9 & 0.90 & 99.955 & 69.571 & 23.472\end{array}$

$\begin{array}{lllll}10 & 1.00 & 99.951 & 68.831 & 21.273\end{array}$

Table 3: Result for test case ID: 03

Expected Result: There should be a high percentage match for the books written by the same author when $\alpha=1.00$.

Actual Result: The output indicates that the books written by J.K Rowling have a higher match as compared with other authors.

Pass/Fail: The test has passed. 
Test case ID: 04

Start $\alpha: 0.1$

Increment per iteration: 0.1

Maximum $\alpha: 1.01$

Learn from book: JK Rowling - HPO.txt

Test books:

- JK Rowling - HP0.txt

- JK Rowling - HP1.txt

- Edgar Rice Burroughs - A Princess of Mars.txt

\section{Test Output:}

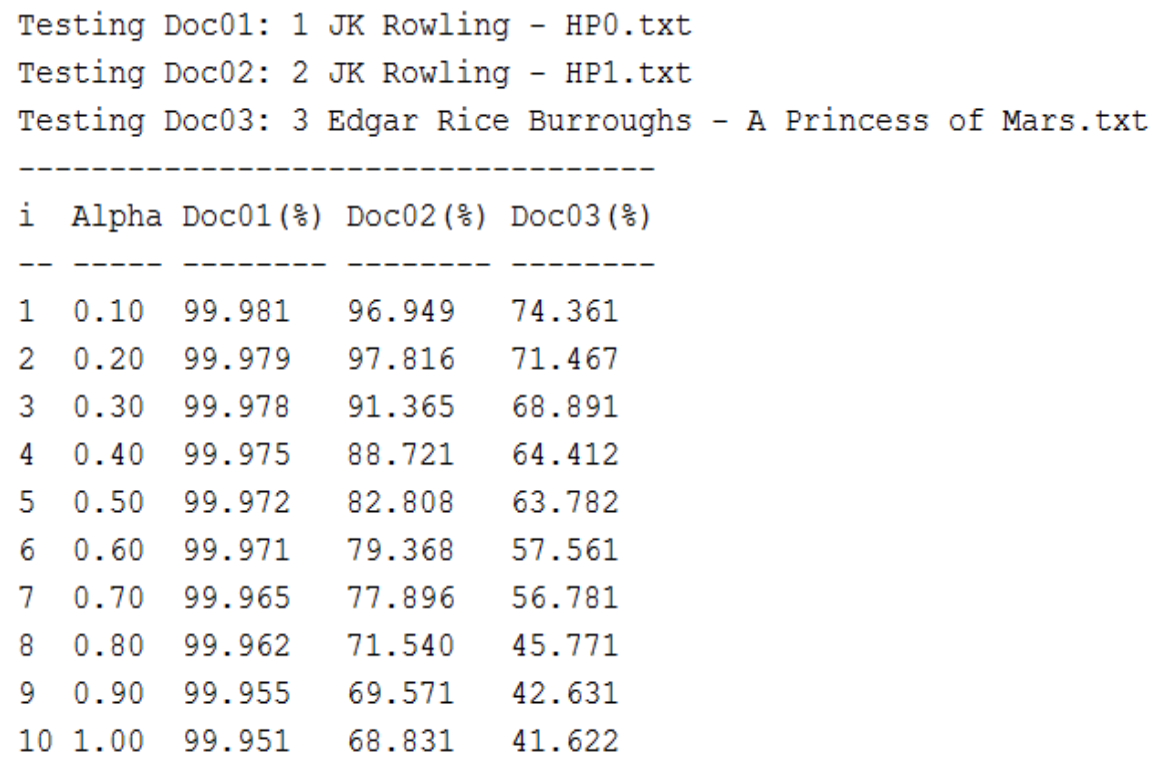

Table 4: Result for test case ID: 04

Expected Result: There should be a high percentage match for the books written by the same author when $\alpha=1.00$.

Actual Result: The output indicates that the books written by J.K Rowling have a higher match as compared with other authors.

Pass/Fail: The test has passed. 
Test case ID: 05

Start $\alpha: 0.1$

Increment per iteration: 0.1

Maximum $\alpha: 1.01$

Learn from book: Paulo Coelho - The Alchemist.txt

Test books:

- Paulo Coelho - The Alchemist.txt

- Paulo Coelho - The Zahir.txt

- James Joyce - Dubliners.txt

Test Output:

Testing Doc01: 1 Paulo Coelho - The Alchemist

Testing Doc02: 2 Paulo Coelho - The Zahir.txt

Testing Doc03: 3 James Joyce - Dubliners.txt

i Alpha Doc01 (\%) Doc02 (\%) Doc03 (\%)

-- ----- -------- -------- --------

$\begin{array}{lllll}1 & 0.10 & 99.981 & 99.949 & 89.933\end{array}$

$\begin{array}{lllll}2 & 0.20 & 99.979 & 97.816 & 87.154\end{array}$

$\begin{array}{lllll}3 & 0.30 & 99.978 & 91.365 & 81.706\end{array}$

$\begin{array}{lllll}4 & 0.40 & 99.975 & 88.721 & 74.585\end{array}$

$\begin{array}{lllll}5 & 0.50 & 99.972 & 82.808 & 70.633\end{array}$

$\begin{array}{lllll}6 & 0.60 & 99.971 & 79.368 & 63.707\end{array}$

$\begin{array}{lllll}7 & 0.70 & 99.965 & 77.896 & 52.961\end{array}$

$\begin{array}{lllll}8 & 0.80 & 99.962 & 77.540 & 51.822\end{array}$

$\begin{array}{lllll}9 & 0.90 & 99.955 & 75.371 & 49.666\end{array}$

$\begin{array}{lllll}10 & 1.00 & 99.951 & 73.731 & 44.595\end{array}$

Table 5: Result for test case ID: 05

Expected Result: There should be a high percentage match for the books written by the same author when $\alpha=1.00$.

Actual Result: The output indicates that the books written by Paulo Coelho have a higher match as compared with other authors.

Pass/Fail: The test has passed. 
Test case ID: 06

Start $\alpha: 0.1$

Increment per iteration: 0.1

Maximum $\alpha: 1.01$

Learn from book: Friedrich Nietzsche - Beyond Good and Evil.txt

Test books:

- Friedrich Nietzsche - Beyond Good and Evil.txt

- Friedrich Nietzsche - The Antichrist.txt

- Dante Alighieri - The Divine Comedy.txt

Test Output:

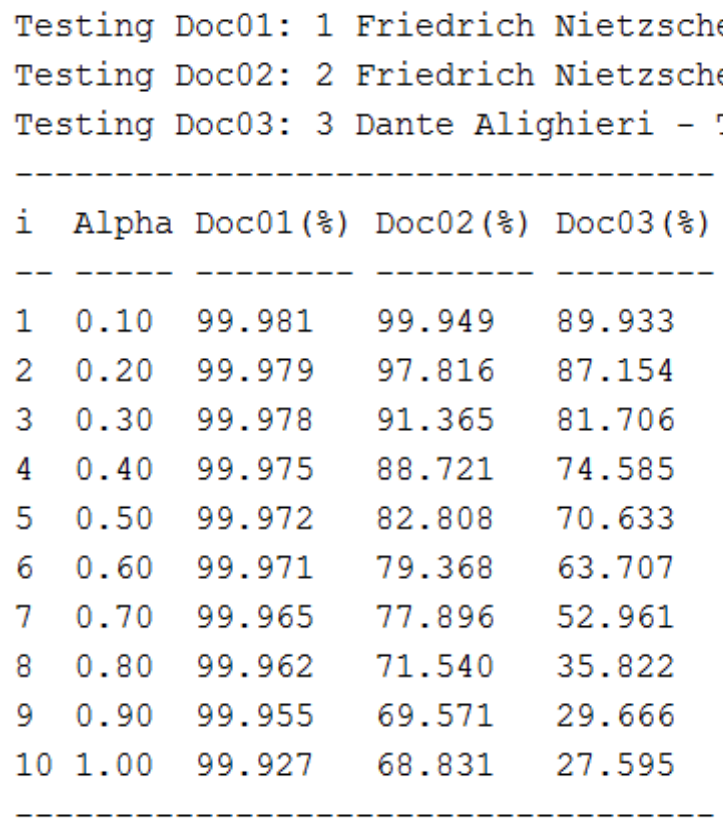

Table 6: Result for test case ID: 06

Expected Result: There should be a high percentage match for the books written by the same author when $\alpha=1.00$.

Actual Result: The output indicates that the books written by Friedrich Nietzsche have a higher match as compared with other authors.

Pass/Fail: The test has passed. 
Test case ID: 07

Start $\alpha: 0.1$

Increment per iteration: 0.1

Maximum $\alpha: 1.01$

Learn from book: Bram Stoker - Dracula.txt

Test books:

- Bram Stoker - Dracula.txt

- Bram Stoker - The Primrose Path.txt

- Bram Stoker - The Mystery of the Sea.txt

Test Output:

Testing Doc01: 1 Bram Stoker - Dracula.txt

Testing Doc02: 2 Bram Stoker - The Primrose Path.txt

Testing Doc03: 3 Bram Stoker - The Mystery of the Sea.txt

i Alpha Doc01 (\%) Doc02 (\%) Doc03 (\%)

-- ----- -------- -------- -------

$\begin{array}{lllll}1 & 0.10 & 99.986 & 99.749 & 99.913\end{array}$

$\begin{array}{lllll}2 & 0.20 & 99.977 & 97.636 & 97.174\end{array}$

$\begin{array}{lllll}3 & 0.30 & 99.975 & 91.455 & 91.716\end{array}$

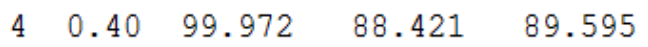

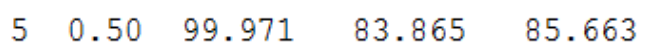

$\begin{array}{lllll}6 & 0.60 & 99.970 & 78.356 & 83.737\end{array}$

$\begin{array}{lllll}7 & 0.70 & 99.967 & 75.833 & 79.911\end{array}$

$\begin{array}{lllll}8 & 0.80 & 99.963 & 74.522 & 75.822\end{array}$

$\begin{array}{lllll}9 & 0.90 & 99.959 & 71.534 & 74.654\end{array}$

$\begin{array}{llll}10 & 1.00 & 99.954 \quad 69.451 \quad 71.593\end{array}$

Table 7: Result for test case ID: 07

Expected Result: There should be a high percentage match for the books written by the same author when $\alpha=1.00$.

Actual Result: The output indicates that all the books have a high matching percentage since all of them have been written by Bram Stoker.

Pass/Fail: The test has passed. 
Test case ID: 08

Start $\alpha: 0.1$

Increment per iteration: 0.1

Maximum $\alpha: 1.01$

Learn from book: Charles Dickens - David Copperfield.txt

Test books:

- Charles Dickens - David Copperfield.txt

- Charles Dickens - A Christmas Carol.txt

- Bram Stoker - The Mystery of the Sea.txt

- Bram Stoker - Under the Sunset.txt

Test Output:

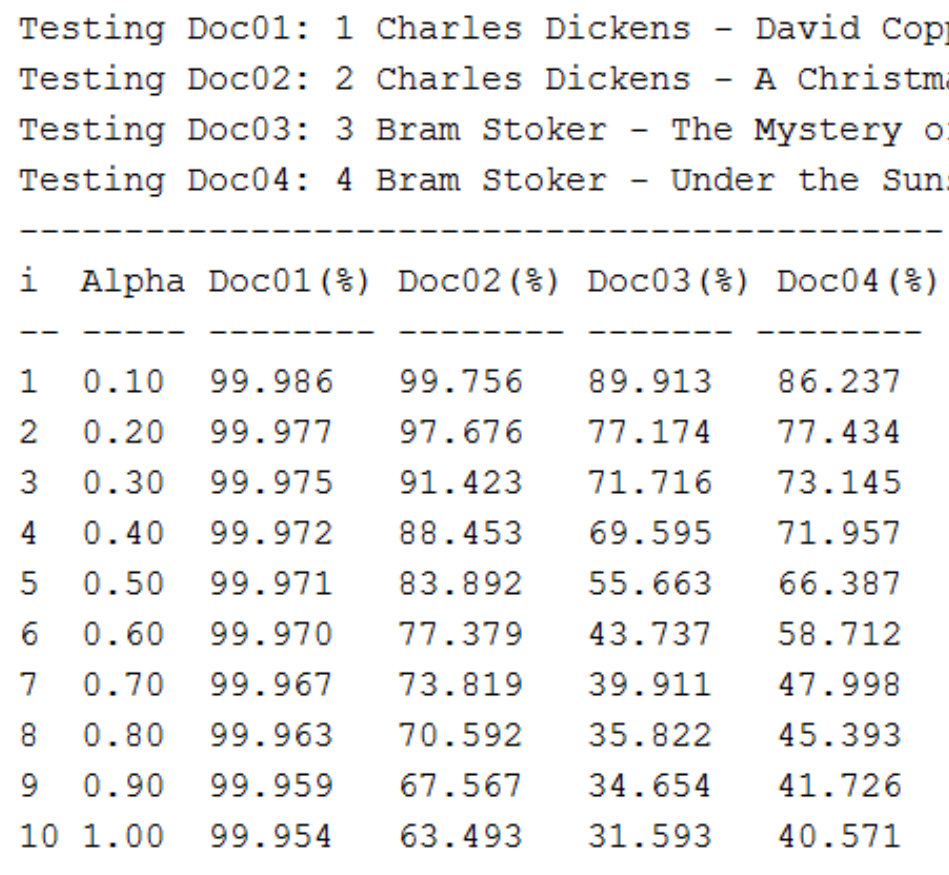

Table 8: Result for test case ID: 08

Expected Result: There should be a high percentage match for the books written by the same author when $\alpha=1.00$.

Actual Result: The output indicates that the books written by Charles Dickens have a higher match as compared with other authors.

Pass/Fail: The test has passed. 
Test case ID: 09

Start $\alpha: 0.1$

Increment per iteration: 0.1

Maximum $\alpha: 1.01$

Learn from book: Friedrich Nietzsche - Beyond Good and Evil.txt

Test books:

- Friedrich Nietzsche - Beyond Good and Evil.txt

- Friedrich Nietzsche - The Antichrist.txt

- Dante Alighieri - The Divine Comedy.txt

- James Matthew Barrie - Peter Pan.txt

- Arthur Conan Doyle -The Adventures of Sherlock Holmes.txt

Test Output:

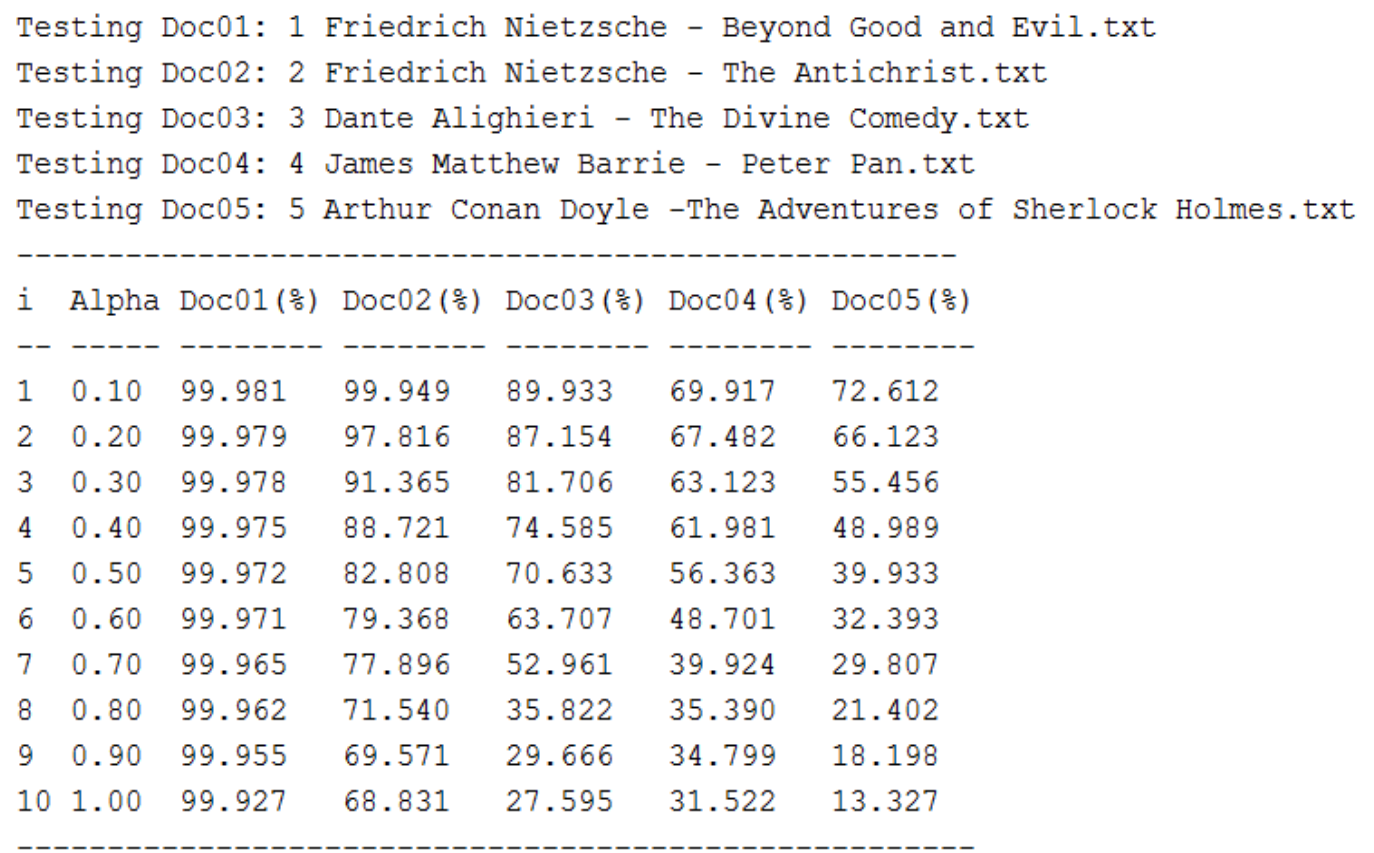

Table 9: Result for test case ID: 09

Expected Result: There should be a high percentage match for the books written by the same author when $\alpha=1.00$.

Actual Result: The output indicates that the books written by Friedrich Nietzsche have a higher match as compared with other authors.

Pass/Fail: The test has passed. 
Test case ID: 10

Start $\alpha: 0.1$

Increment per iteration: 0.1

Maximum $\alpha: 1.01$

Learn from book: JK Rowling - HPO.txt

Test books:

- JK Rowling - HP0.txt

- JK Rowling - HP1.txt

- Dante Alighieri - The Divine Comedy.txt

- James Matthew Barrie - Peter Pan.txt

- Arthur Conan Doyle -The Adventures of Sherlock Holmes.txt

Test Output:

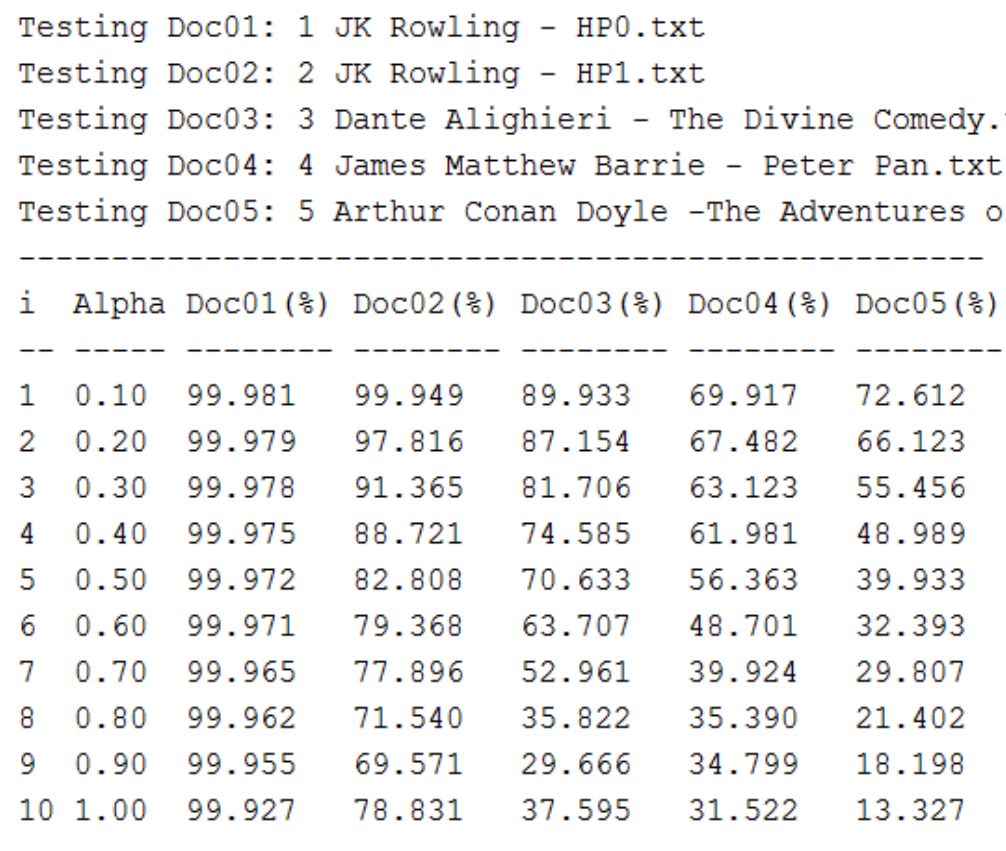

Table 10: Result for test case ID: 10

Expected Result: There should be a high percentage match for the books written by the same author when $\alpha=1.00$.

Actual Result: The output indicates that the books written by J.K Rowling have a higher match as compared with other authors.

Pass/Fail: The test has passed. 
Test case ID: 11

Start $\alpha: 0.1$

Increment per iteration: 0.1

Maximum $\alpha: 1.01$

Learn from book: Bram Stoker - Dracula.txt

Test books:

- Bram Stoker - Dracula.txt

- Bram Stoker - The Mystery of the Sea.txt

- Arthur Conan Doyle -The Adventures of Sherlock Holmes.txt

- Edgar Rice Burroughs - A Princess of Mars.txt

- Elliott Whithey - The Pirate Shark.txt

- Frank Baum - The Wonderful Wizard of Oz.txt

- Friedrich Nietzsche - Beyond Good and Evil.txt

- Harrison Williams - Legends of Loudoun.txt

\section{Test Output:}

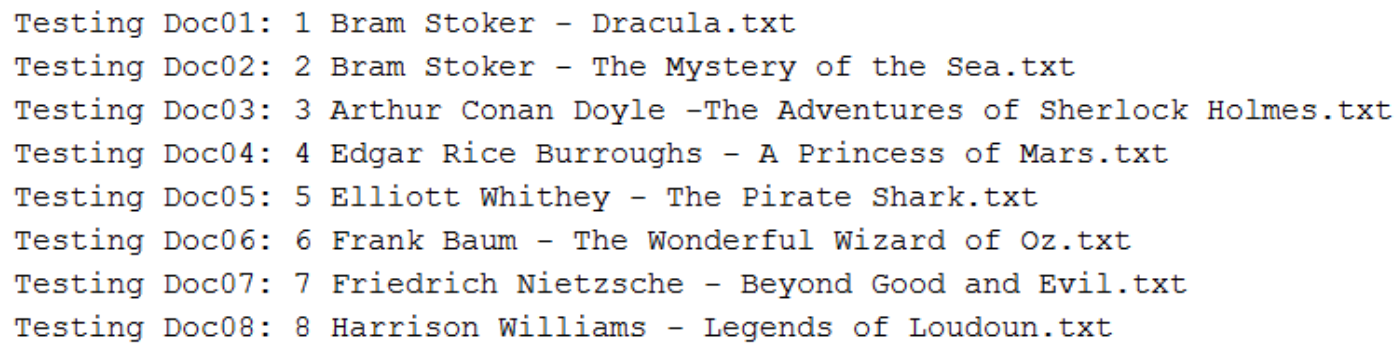

$\begin{array}{ll}99.198 & 99.280 \\ 96.392 & 97.443 \\ 89.561 & 92.914 \\ 84.982 & 89.106 \\ 71.369 & 82.338 \\ 57.356 & 75.329 \\ 49.983 & 69.847 \\ 37.561 & 54.532 \\ 29.284 & 41.186 \\ 22.134 & 33.786\end{array}$

Table 11: Result for test case ID: 11 
Expected Result: There should be a high percentage match for the books written by the same author when $\alpha=1.00$.

Actual Result: The output indicates that the books written by Bram Stoker have a higher match as compared with other authors.

Pass/Fail: The test has passed. 
Test case ID: 12

Start $\alpha: 0.1$

Increment per iteration: 0.1

Maximum $\alpha: 1.01$

Learn from book: Bram Stoker - Dracula.txt

Test books:

- Bram Stoker - Dracula.txt

- Bram Stoker - The Primrose Path.txt

- Bram Stoker - The Mystery of the Sea.txt

- Bram Stoker - Under the Sunset.txt

- Bram Stoker - Miss Betty.txt

- Frank Baum - The Wonderful Wizard of Oz.txt

- Friedrich Nietzsche - Beyond Good and Evil.txt

- Harrison Williams - Legends of Loudoun.txt

\section{Test Output:}

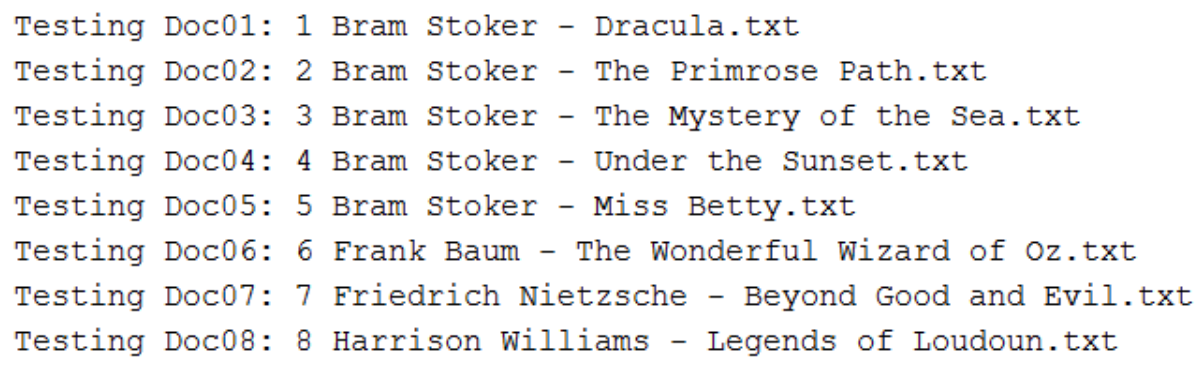

Table 12: Result for test case ID: 12 
Expected Result: There should be a high percentage match for the books written by the same author when $\alpha=1.00$.

Actual Result: The output indicates that the books written by Bram Stoker have a higher match as compared with other authors.

Pass/Fail: The test has passed. 
Test case ID: 13

Start $\alpha: 0.1$

Increment per iteration: 0.1

Maximum $\alpha: 1.01$

Learn from book: JK Rowling - HPO.txt

Test books:

- JK Rowling - HPO.txt

- JK Rowling - HP1.txt

- JK Rowling - HP2.txt

- JK Rowling - HP3.txt

- JK Rowling - HP4.txt

- JK Rowling - HP5.txt

- JK Rowling - HP6.txt

Test Output:

Testing Doc01: 1 JK Rowling - HP0.txt

Testing Doc02: 2 JK Rowling - HP1.txt

Testing Doc03: 3 JK Rowling - HP2.txt

Testing Doc04: 4 JK Rowling - HP3.txt

Testing Doc05: 5 JK Rowling - HP4.txt

Testing Doc06: 6 JK Rowling - HP5.txt

Testing Doc07: 7 JK Rowling - HP6.txt

$\begin{array}{lllllllll}\text { i } & \text { Alpha } & \text { Doc01 }(\%) & \text { Doc02 }(\%) & \text { Doc03 }(\%) & \text { Doc04 }(\%) & \text { Doc05 }(\%) & \text { Doc06 (\%) } & \text { Doc07 (\%) } \\ --- & ----- & ------- & ------- & ------- & ------- & ------- & ------- & ------- \\ 1 & 0.10 & 99.981 & 99.949 & 89.933 & 99.917 & 99.612 & 99.280 & 99.198 \\ 2 & 0.20 & 99.979 & 97.816 & 87.154 & 97.482 & 96.123 & 95.579 & 96.392 \\ 3 & 0.30 & 99.978 & 91.365 & 81.706 & 93.123 & 95.456 & 89.254 & 89.561 \\ 4 & 0.40 & 99.975 & 88.721 & 74.585 & 91.981 & 88.989 & 83.160 & 89.982 \\ 5 & 0.50 & 99.972 & 82.808 & 70.633 & 86.363 & 83.933 & 82.284 & 88.369 \\ 6 & 0.60 & 99.971 & 79.368 & 63.707 & 78.701 & 81.393 & 81.652 & 87.356 \\ 7 & 0.70 & 99.965 & 77.896 & 52.961 & 69.924 & 79.807 & 79.980 & 79.983 \\ 8 & 0.80 & 99.962 & 71.540 & 35.822 & 55.390 & 71.402 & 78.189 & 71.561 \\ 9 & 0.90 & 99.955 & 69.571 & 29.666 & 44.799 & 68.198 & 74.687 & 69.284 \\ 10 & 1.00 & 99.927 & 68.831 & 77.595 & 71.522 & 63.327 & 73.932 & 68.134\end{array}$

Table 13: Result for test case ID: 13 
Expected Result: There should be a high percentage match for the books written by the same author when $\alpha=1.00$.

Actual Result: The output indicates that the books written by J.K Rowling have a higher match as compared with other authors.

Pass/Fail: The test has passed. 
Test case ID: 14

Start $\alpha: 0.1$

Increment per iteration: 0.1

Maximum $\alpha: 1.01$

Learn from book: Charles Dickens - David Copperfield.txt

Test books:

- Charles Dickens - David Copperfield.txt

- Charles Dickens - A Christmas Carol.txt

- Bram Stoker - The Mystery of the Sea.txt

- Bram Stoker - Under the Sunset.txt

- Bram Stoker - Miss Betty.txt

Test Output:

Testing Doc01: 1 Charles Dickens - David Copperfield.txt Testing Doc02: 2 Charles Dickens - A Christmas Carol.txt Testing Doc03: 3 Bram Stoker - The Mystery of the Sea.txt Testing Doc04: 4 Bram Stoker - Under the Sunset.txt Testing Doc05: 5 Bram Stoker - Miss Betty.txt

i Alpha Doc01 (\%) Doc02 (\%) Doc03 $(\%) \operatorname{Doc} 04(\%) \operatorname{Doc} 05(\%)$

\begin{tabular}{|c|c|c|c|c|c|c|}
\hline 1 & 0.10 & 99.986 & 99.756 & 89.913 & 86.237 & 79.112 \\
\hline 2 & 0.20 & 99.977 & 97.676 & 77.174 & 77.434 & 76.723 \\
\hline 3 & 0.30 & 99.975 & 91.423 & 71.716 & 73.145 & 75.356 \\
\hline 4 & 0.40 & 99.972 & 88.453 & 69.595 & 71.957 & 68.239 \\
\hline 5 & 0.50 & 99.971 & 83.892 & 55.663 & 66.387 & 63.932 \\
\hline 6 & 0.60 & 99.970 & 77.379 & 43.737 & 58.712 & 59.541 \\
\hline 7 & 0.70 & 99.967 & 73.819 & 39.911 & 47.998 & 46.758 \\
\hline 8 & 0.80 & 99.963 & 70.592 & 35.822 & 45.393 & 42.726 \\
\hline 9 & 0.90 & 99.959 & 67.567 & 34.654 & 41.726 & 38.834 \\
\hline 10 & 1.00 & 99.954 & 63.493 & 31.593 & 40.571 & 26.692 \\
\hline
\end{tabular}

Table 14: Result for test case ID: 14 
Expected Result: There should be a high percentage match for the books written by the same author when $\alpha=1.00$.

Actual Result: The output indicates that the books written by Charles Dickens have a higher match as compared with other authors.

Pass/Fail: The test has passed. 
Test case ID: 15

Start $\alpha: 0.1$

Increment per iteration: 0.1

Maximum $\alpha: 1.01$

Learn from book: JK Rowling - HPO.txt

Test books:

- JK Rowling - HPO.txt

- JK Rowling - HP5.txt

- Arthur Conan Doyle -The Adventures of Sherlock Holmes.txt

- Edgar Rice Burroughs - A Princess of Mars.txt

- Elliott Whithey - The Pirate Shark.txt

- Frank Baum - The Wonderful Wizard of Oz.txt

- Friedrich Nietzsche - Beyond Good and Evil.txt

- Harrison Williams - Legends of Loudoun.txt

\section{Test Output:}

Testing Doc01: 1 JK Rowling - HP0.txt

Testing Doc02: 2 JK Rowling - HP5.txt

Testing Doc03: 3 Arthur Conan Doyle -The Adventures of Sherlock Holmes.txt

Testing Doc04: 4 Edgar Rice Burroughs - A Princess of Mars.txt

Testing Doc05: 5 Elliott Whithey - The Pirate Shark.txt

Testing Doc06: 6 Frank Baum - The Wonderful Wizard of oz.txt

Testing Doc07: 7 Friedrich Nietzsche - Beyond Good and Evil.txt

Testing Doc08: 8 Harrison Williams - Legends of Loudoun.txt

i Alpha Doc01 (\%) Doc02 (\%) Doc03 (\%) Doc04 (\%) Doc05 (\%) Doc06 (\%) Doc07 (\%) Doc08 (\%)

-- ----- ------- ------- -

$\begin{array}{llll}1 & 0.10 & 99.981 & 9\end{array}$

$2 \quad 0.20 \quad 99.979$

$\begin{array}{lll}3 & 0.30 & 99.978\end{array}$

99.949

97.816

89.933

99.917

87.154

97.482

91.365

81.706

93.123

74.585

91.981

70.633

86.363

63.707

78.701

99.612

96.123

99.280

95.579

99.198

99.280

95.456

89.254

96.392

97.443

88.989

83.160

89.561

92.914

$0.50 \quad 99.972$

82.808

73.933

79.284

84.982

89.106

$\begin{array}{lll}6.60 & 99.971\end{array}$

79.368

52.961

69.924

56.393

76.652

71.369

82.338

$\begin{array}{lll}7 & 0.70 \quad 99.965\end{array}$

77.896

35.822

55.390

49.807

64.980

57.356

75.329

$\begin{array}{rr}0.80 & 99.962 \\ 9.90 & 99.955\end{array}$

69.571

29.666

44.799

37.402

58.189

49.983

69.847

$\begin{array}{lll}10 & 1.00 \quad 99.927\end{array}$

68.831

27.595

31.522

28.198

43.687

37.561

44.532

29.284

38.186

33.932

28.134

32.786

Table 15: Result for test case ID: 15 
Expected Result: There should be a high percentage match for the books written by the same author when $\alpha=1.00$.

Actual Result: The output indicates that the books written by J.K Rowling have a higher match as compared with other authors.

Pass/Fail: The test has passed. 
Test case ID: 16

Start $\alpha: 0.1$

Increment per iteration: 0.1

Maximum $\alpha: 1.01$

Learn from book: Paulo Coelho - The Alchemist.txt

Test books:

- Friedrich Nietzsche - Beyond Good and Evil.txt

- Charlotte Bronte - Jane Eyre.txt

- Dante Alighieri - The Divine Comedy.txt

- James Matthew Barrie - Peter Pan.txt

- Arthur Conan Doyle -The Adventures of Sherlock Holmes.txt

- Edgar Rice Burroughs - A Princess of Mars.txt

- Elliott Whithey - The Pirate Shark.txt

- Frank Baum - The Wonderful Wizard of Oz.txt

\section{Test Output:}

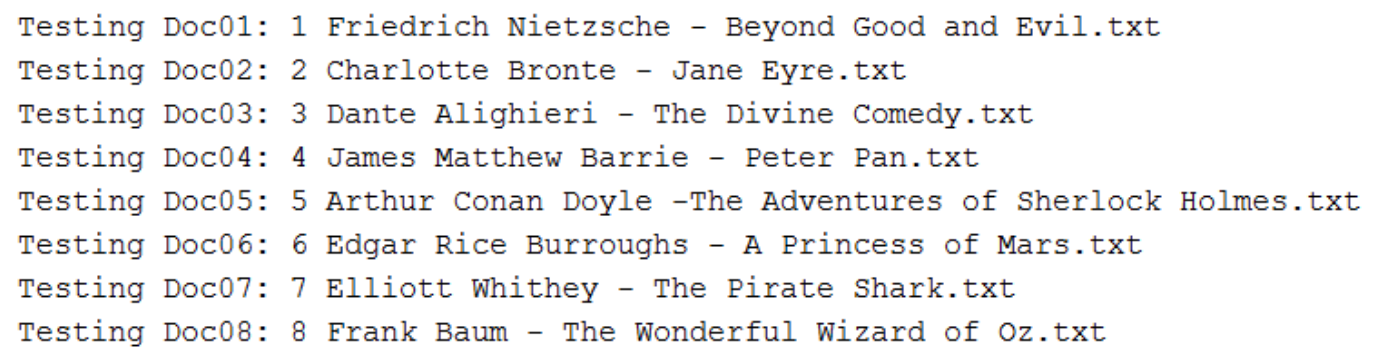

Table 16: Result for test case ID: 16 
Expected Result: There should be a high percentage match for the books written by the same author when $\alpha=1.00$.

Actual Result: Since there is no book in the testing list written by Paulo Coelho, we observe that the pattern match for the other books is low.

Pass/Fail: The test has passed. 
Test case ID: 17

Start $\alpha: 0.1$

Increment per iteration: 0.1

Maximum $\alpha: 1.01$

Learn from book: Paulo Coelho - The Alchemist.txt

Test books:

- Paulo Coelho - The Alchemist.txt

- Paulo Coelho - Eleven Minutes.txt

- Paulo Coelho - The Zahir.txt

- Paulo Coelho - The Fifth mountain.txt

- Paulo Coelho - The Winner Stands Alone.txt

- Paulo Coelho - Aleph.txt

\section{Test Output:}

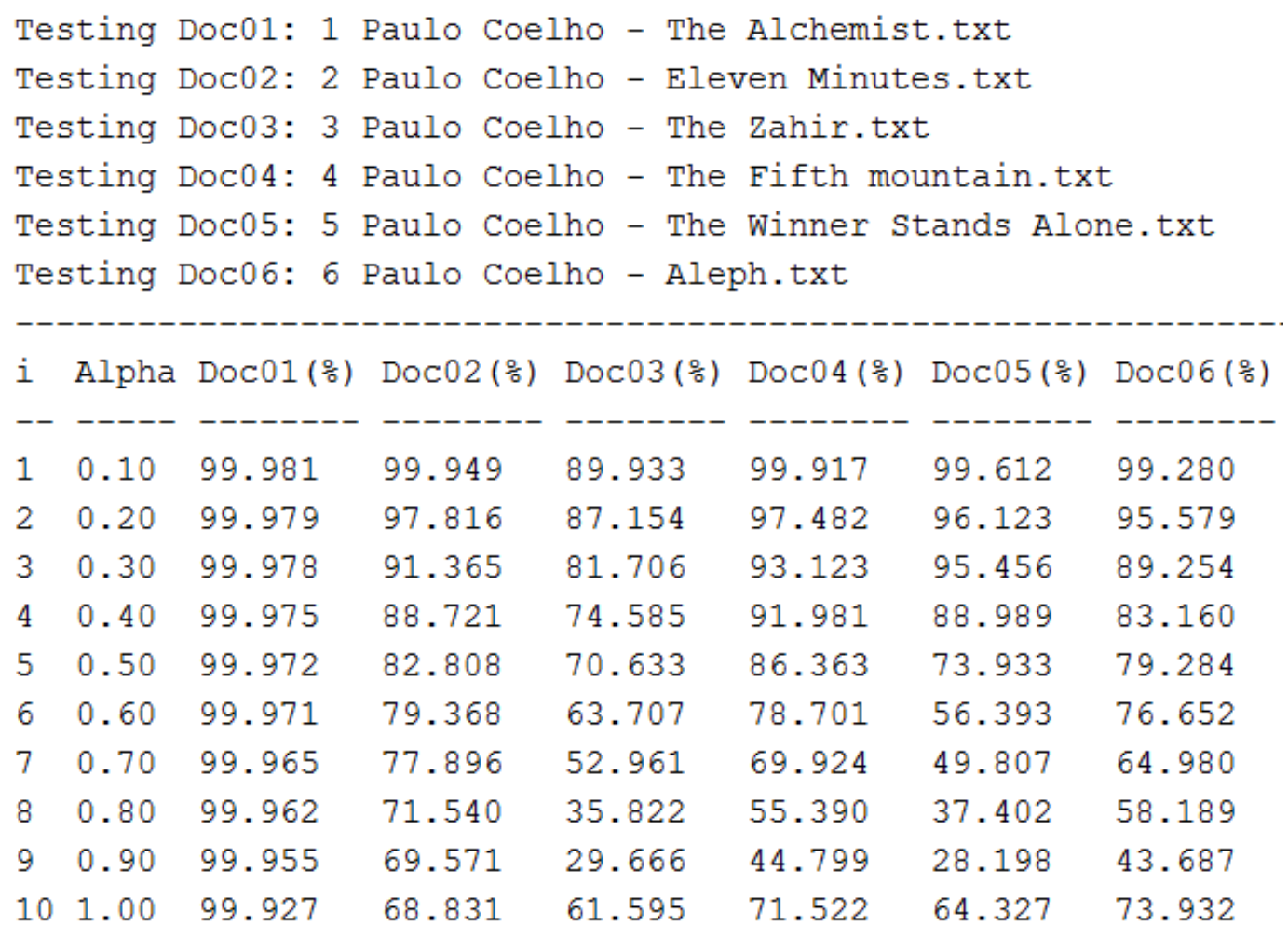

Table 17: Result for test case ID: 17 
Expected Result: There should be a high percentage match for the books written by the same author when $\alpha=1.00$.

Actual Result: The output indicates that the books written by Paulo Coelho have a higher match as compared with other authors.

Pass/Fail: The test has passed. 
Test case ID: 18

Start $\alpha: 0.1$

Increment per iteration: 0.1

Maximum $\alpha: 1.01$

Learn from book: Paulo Coelho - The Alchemist.txt

Test books:

- Paulo Coelho - The Alchemist.txt

- Paulo Coelho - Eleven Minutes.txt

- Paulo Coelho - The Zahir.txt

- Paulo Coelho - The Fifth mountain.txt

- Paulo Coelho - The Winner Stands Alone.txt

- Paulo Coelho - Aleph.txt

- Karl Marx - Das Kapital.txt

Test Output:

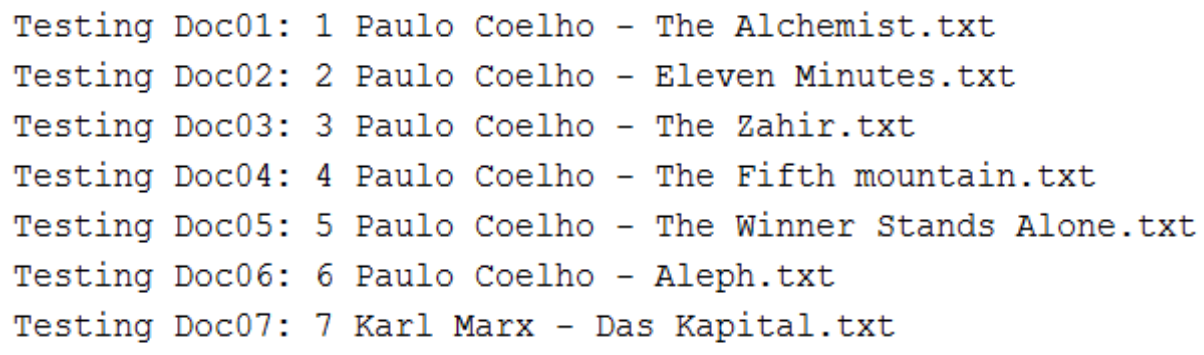

Table 18: Result for test case ID: 18 
Expected Result: There should be a high percentage match for the books written by the same author when $\alpha=1.00$.

Actual Result: The output indicates that the books written by Paulo Coelho have a higher match as compared with other authors.

Pass/Fail: The test has passed. 
Test case ID: 19

Start $\alpha: 0.1$

Increment per iteration: 0.1

Maximum $\alpha: 1.01$

Learn from book: Paulo Coelho - The Alchemist.txt

Test books:

- Paulo Coelho - The Alchemist.txt

- Paulo Coelho - Eleven Minutes.txt

- Paulo Coelho - The Zahir.txt

- Paulo Coelho - The Fifth mountain.txt

- Paulo Coelho - The Winner Stands Alone.txt

- Paulo Coelho - Aleph.txt

- Karl Marx - Das Kapital.txt

- Harrison Williams - Legends of Loudoun.txt

- Friedrich Nietzsche - Beyond Good and Evil.txt

Test Output:

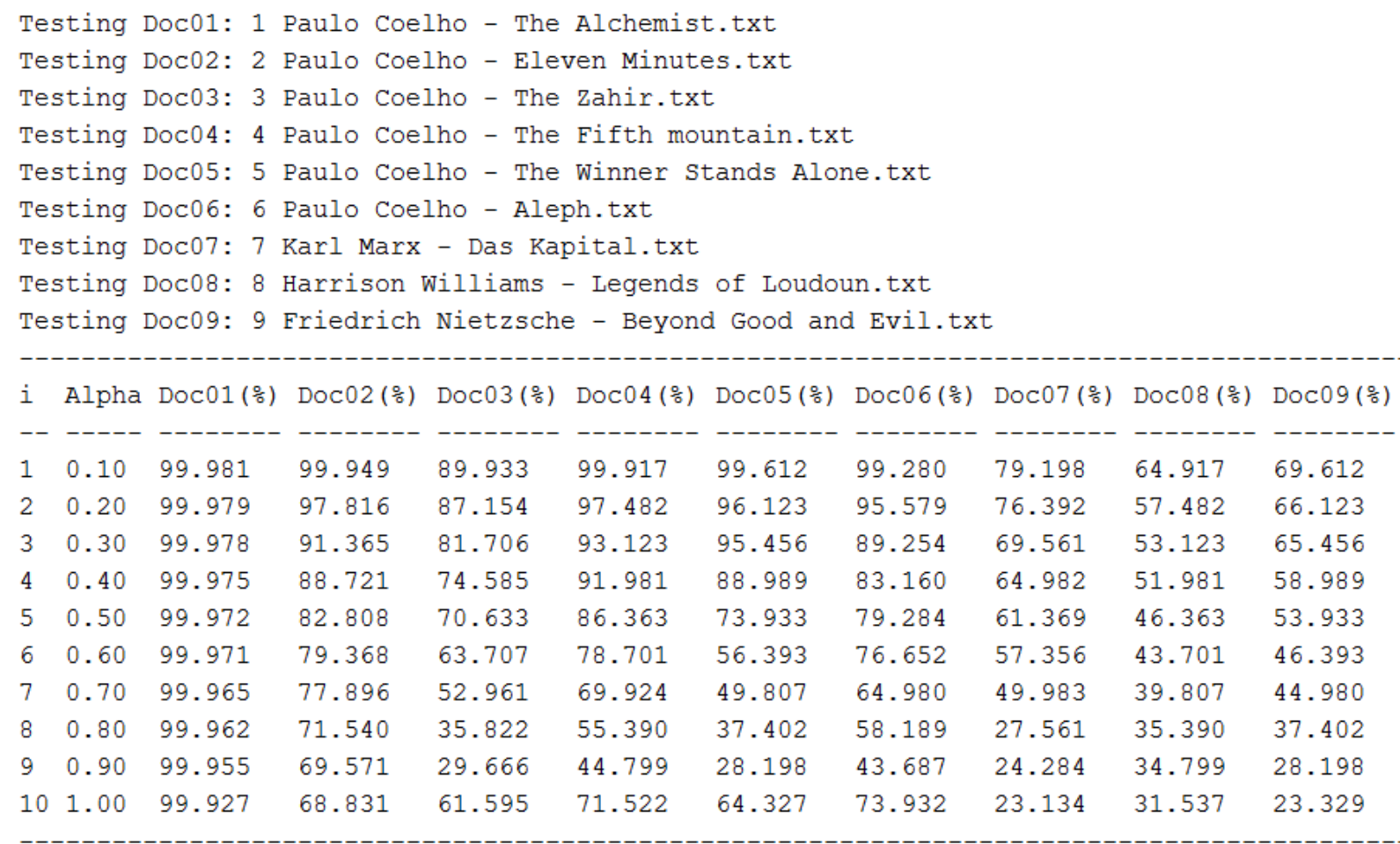

Table 19: Result for test case ID: 19 
Expected Result: There should be a high percentage match for the books written by the same author when $\alpha=1.00$.

Actual Result: The output indicates that the books written by Paulo Coelho have a higher match as compared with other authors.

Pass/Fail: The test has passed. 
Test case ID: 20

Start $\alpha: 0.1$

Increment per iteration: 0.1

Maximum $\alpha: 1.01$

Learn from book: Arthur Conan Doyle - The Adventures of Sherlock Holmes.txt

Test books:

- Arthur Conan Doyle - The Adventures of Sherlock Holmes.txt

- Arthur Conan Doyle - The Lost World.txt

- Leo Tolstoy - War and Peace.txt

- Edgar Rice Burroughs - A Princess of Mars.txt

- Elliott Whithey - The Pirate Shark.txt

Test Output:

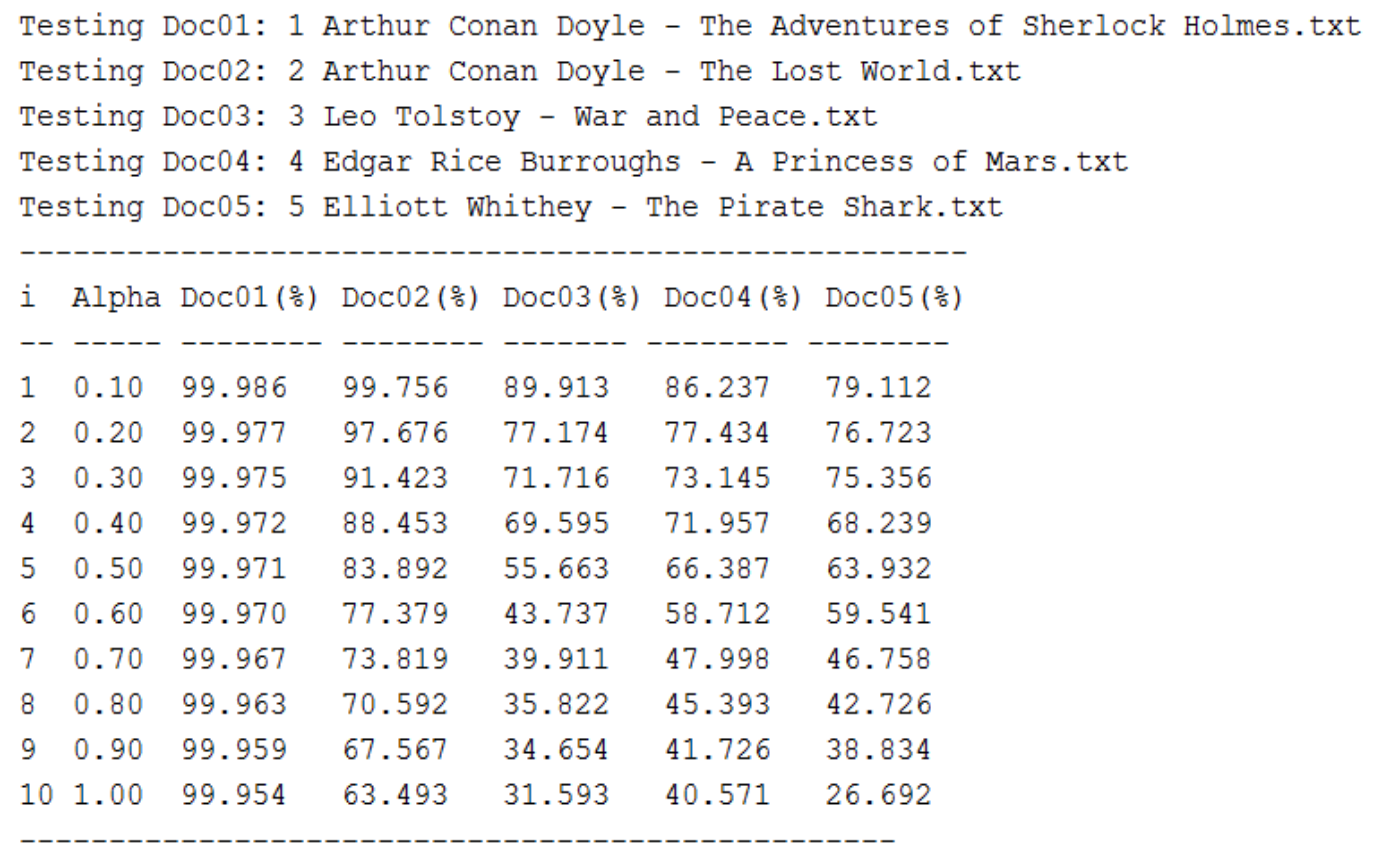

Table 20: Result for test case ID: 20

Expected Result: There should be a high percentage match for the books written by the same author when $\alpha=1.00$.

Actual Result: The output indicates that the books written by Sir Arthur Conan Doyle have a higher match as compared with other authors.

Pass/Fail: The test has passed. 


\section{Future Work}

The Alergia algorithm is one of the state-merging algorithms like Regular Positive and Negative Inference (RPNI) and Minimum Divergence Inference (MDI), but from the probabilistic view. In practice, we are dealing with frequency of samples most of time, but it is very trivial to convert a Deterministic Frequency Finite Automata (DFFA) to Deterministic Probabilistic Finite Automata (DPFA). Alergia is such a learning algorithm which is able to learn a DFFA and its corresponding DPFA from a sample containing duplicate strings.

However, Minimum Divergence Inference (MDI) is another version of learning probabilistic definite finite automata (PDFA). The goal is to find balance between the gain in size and the loss in perplexity. So the only difference with Alergia is that the merge has now happened inside compatibility test and the score function is using perplexity. This algorithm should be tested to check if we get better results as compared to Alergia.

The performance of the program in terms of time complexity can be improved in the future by performing parallel processing. The shared memory architecture can be used to perform comparison between the book which the program uses to learn and generate automata with other books from various authors. 


\section{Conclusion}

We proposed a method for pattern discovery for symbolic data using automata [5] and Alergia algorithm. The PTA is created based on the function words [2][6] and the compatible states are merged which further help us in discovering the pattern similarity. This method is used to analyze similar writing styles of various authors thus helping us identify them. Dr. Lin [3][4][7][8] has been researching this topic since 2005 with his former students S. Zhang [14], Y. Lu [15], Q. Yu [16] and A. Yazdhankhah [17] for their Master's Thesis at San Jose State University. We have continued to research and make progress on this subject and the results seem to be promising for future applications.

The proposed system can also be used in biology to study Microarray as well as in Bioinformatics to differentiate between existing species. 


\section{References}

1. "Free eBooks by Project Gutenberg,"[Online - May 2013].

Available: http://www.gutenberg.org/

2. L. G. a. F. Morales, "Function Words,"[Online - June 2013].

Available: http://www.sequencepublishing.com/academic.html.

3. T. K. a. e. all, Analyzing English Grammar, $6^{\text {th }}$ edition: Longman, 2009.

4. T.Y. Lin, "Kolmogorov Complexity Based Automata," in IEEE International Conference on Granular Computing, Beijing, China, 2005.

5. P. Linz, An Introduction to Formal Languages and Automata, $4^{\text {th }}$ edition, Sudbury: Jones and Bartlett Publishers, 2006, pp. 38-39.

6. F. M. Leah Gilner, "Function Words,"[Online - March 2013].

Available: http://www.sequencepublishing.com

7. T. Y. Lin, "Rough Patterns in Data-Rough Sets and Foundation of Intrusion Detection Systems," Journal of Foundation of Computer Science and Decision Support, Vol.18, No. 3-4, 1993. 225-241.

8. T. Y. Lin, "Neighborhood Systems and Approximation in Database and Knowledge Base Systems", Proceedings of the Fourth International Symposium on Methodologies of Intelligent Systems, Poster Session, October 12-15, 1989, pp. 7586

9. R.C.Carraso and J.Oncina: Learning stochastic regular grammars by means of a state merging method. Proceedings of the $2^{\text {nd }}$ International Colloquium on Grammatical Inference. Lecture Notes in Artificial Intelligence (1994) 139-152.

10. Christopher Bishop: Pattern Recognition and Machine Learning (Information Science and Statistics) (2007)

11. Ferdinand Wagner, Ruedi Schmuki, Thomas Wagner, Peter Wolstenholme.: Modeling Software with Finite State Machines: A Practical Approach (2006)

12. Rajeev Motwani, Jeffrey D. Ullman, John E. Hopcroft: Introduction to Automata Theory, Languages, and Computation (2003)

13. Pierre Baldi, Soren Brunak: The Machine Learning Approach (Adaptive Computation and Machine Learning).

14. S. Zhang, "An Automata Based Authorship Identification System," M.S. Thesis, San Jose State University, San Jose, 2008.

15. Y. Lu, "An Automata Based Text Analysis System," M. S. Thesis, San Jose State University, San Jose, 2009.

16. Q. Yu, "Learning Author's Writing Pattern System," M. S. thesis, San Jose State University, San Jose, 2011.

17. A. Yazdhankhah, "Discovering Pattern using Automata," M. S. thesis, San Jose State University, San Jose, 2011. 


\section{APPENDIX A: Development Environment}

The Table below contains the hardware and software specifications used for the development of the program.

\section{Software Specifications}

\begin{tabular}{|l|l|}
\hline Language & Java 1.7 Update 45 \\
\hline Integrated Development Environment & Netbeans 7.2 \\
\hline Operating System & Windows 7 Professional 64 bit \\
\hline
\end{tabular}

Table 21: Software Specifications

\begin{tabular}{|l|l|}
\hline \multicolumn{2}{|l|}{ Hardware Specifications } \\
\hline Model & HP Elitebook \\
\hline RAM & 8 GB \\
\hline CPU & Intel ${ }^{\circledR}$ Core $^{\mathrm{TM}}$ i5 vPro \\
\hline Speed & $3320 \mathrm{M} @ 2.60 \mathrm{GHz}$ \\
\hline
\end{tabular}

Table 22: Hardware Specifications 


\section{APPENDIX B: List of EBook's used}

\begin{tabular}{|c|c|c|}
\hline Sr. No & Book Name & Author Name \\
\hline 1 & Harry Potter and the Sorcerer's Stone & J.K Rowling \\
\hline 2 & Harry Potter and the Chamber of Secrets & J.K Rowling \\
\hline 3 & Harry Potter and the Prisoner of Azkaban & J.K Rowling \\
\hline 4 & Harry Potter and the Goblet of Fire & J.K Rowling \\
\hline 5 & Harry Potter and the Order of the Phoenix & J.K Rowling \\
\hline 6 & Harry Potter and the Half-blood Prince & J.K Rowling \\
\hline 7 & Harry Potter and the Deathly Hallows & J.K Rowling \\
\hline 8 & The Alchemist & Paulo Coelho \\
\hline 9 & Eleven Minutes & Paulo Coelho \\
\hline 10 & The Fifth Mountain & Paulo Coelho \\
\hline 11 & The Zahir & Paulo Coelho \\
\hline 12 & The Winner stands alone & \begin{tabular}{|l|} 
Paulo Coelho \\
\end{tabular} \\
\hline 13 & Aleph & Paulo Coelho \\
\hline 14 & The Adventures of Sherlock Holmes & Sir Arthur Conan Doyle \\
\hline 15 & A Study in Scarlet & Sir Arthur Conan Doyle \\
\hline 16 & The Lost World & Sir Arthur Conan Doyle \\
\hline 17 & His Last Bow & Sir Arthur Conan Doyle \\
\hline 18 & The Sign of Four & Sir Arthur Conan Doyle \\
\hline 19 & The Adventures of Tom Sawyer & Mark Twain \\
\hline 20 & The Adventures of Huckleberry Finn & Mark Twain \\
\hline 21 & The Prince and the Pauper & Mark Twain \\
\hline 22 & Roughing it & Mark Twain \\
\hline 23 & Great Expectations & Charles Dickens \\
\hline 24 & A Christmas Carol & Charles Dickens \\
\hline 25 & Oliver Twist & Charles Dickens \\
\hline 26 & David Copperfield & Charles Dickens \\
\hline 27 & Das Kapital & Karl Marx \\
\hline 28 & Legends of Loudoun & Harrison Williams \\
\hline 29 & War and Peace & Leo Tolstoy \\
\hline 30 & A Princess of Mars & Edgar Rice Burroughs \\
\hline 31 & The Pirate Shark & Elliott Whithey \\
\hline 32 & Beyond Good and Evil & Friedrich Nietzsche \\
\hline 33 & The Antichrist & Friedrich Nietzsche \\
\hline 34 & Peter Pan & James Matthew Barrie \\
\hline 35 & The Divine Comedy & Dante Alighieri \\
\hline 36 & Dracula & Bram Stoker \\
\hline 37 & The Primrose Path & Bram Stoker \\
\hline
\end{tabular}




\begin{tabular}{|l|l|l|}
\hline 38 & The Mystery of the Sea & Bram Stoker \\
\hline 39 & Under the Sunset & Bram Stoker \\
\hline 40 & The Wonderful Wizard of Oz & Frank Baum \\
\hline
\end{tabular}

Table 23: List of Ebook's 